\title{
Effects of Glyphosate Application on Physiologically Integrated Clones of the Invasive Plant Carpobrotus edulis
}

\author{
Sergio R. Roiloa ${ }^{1, *(\mathbb{D})}$, Fei-Hai Yu ${ }^{2,3}$ [D and Rodolfo Barreiro ${ }^{1}$ (i) \\ 1 BioCost Group, Department of Biology, Faculty of Science, Universidade da Coruña, 15071 A Coruña, Spain; \\ rodolfo.barreiro@udc.es \\ 2 Institute of Wetland Ecology \& Clone Ecology, Taizhou University, Taizhou 318000, China; feihaiyu@126.com \\ 3 Zhejiang Provincial Key Laboratory of Plant Evolutionary Ecology and Conservation, Taizhou 318000, China \\ * Correspondence: sergio.roiloa@udc.es
}

check for

updates

Citation: Roiloa, S.R.; Yu, F.-H.;

Barreiro, R. Effects of Glyphosate Application on Physiologically Integrated Clones of the Invasive Plant Carpobrotus edulis. Diversity 2022, 14, 47. https://doi.org/ 10.3390/d14010047

Academic Editors: Juan Bautista Gallego Fernández and Panayiotis Dimitrakopoulos

Received: 19 November 2021 Accepted: 11 January 2022

Published: 12 January 2022

Publisher's Note: MDPI stays neutral with regard to jurisdictional claims in published maps and institutional affiliations.

Copyright: (C) 2022 by the authors. Licensee MDPI, Basel, Switzerland. This article is an open access article distributed under the terms and conditions of the Creative Commons Attribution (CC BY) license (https:// creativecommons.org/licenses/by/ $4.0 /)$.

\begin{abstract}
Management of invasive alien species is a high priority for biodiversity conservation. Here, we studied the effects of glyphosate application, at $0.06 \mathrm{~g} / \mathrm{m}^{2}$ concentration, on physiologically integrated basal and apical ramets of the invasive clonal plant Carpobrotus edulis. Physiological integration allows the transport of resources and other substances between connected ramets in clonal plants. We found a significant reduction of growth and photochemical efficiency both in basal and apical ramets of $C$. edulis after glyphosate application. Interestingly, we also observed a significant growth reduction in untreated basal ramets when they remained connected to apical ramets treated with glyphosate. This result was interpreted as a cost for basal ramets due to supporting severely stressed apical ramets. Therefore, local application of glyphosate to apical ramets of C. edulis can negatively affect not only their own growth, but also the growth of their interconnected, untreated basal ramets. Our results suggest that glyphosate effectiveness can be maintained when applied only to one part of the clone so that the amount of herbicide used in eradication programs can be greatly reduced, which can minimize the negative impact of chemical herbicides on ecosystems.
\end{abstract}

Keywords: biological invasions; biomass partitioning; Carpobrotus; chemical control; chlorophyll fluorescence; clonal growth; division of labour; glyphosate; photochemical activity; physiological integration

\section{Introduction}

Coastal sand dunes are fragile ecosystems that usually contain both endemic and endangered species, and are a key objective for biodiversity conservation [1]. Biological invasions represent one of largest threats to natural ecosystems, including coastal sand dunes [2]. In particular, the presence of invasive plant species represents a direct threat to native plant species by, for instance, displacing them locally and even driving them to extinction [3-5]. Invasive species may cause indirect effects on native plant species by modifying biotic and abiotic conditions of native communities and ecosystems [6]. Invasive species can also damage ecosystem services and cause huge economic cost to society worldwide [7]. Thus, the management of invasive alien species is a high priority for countries around the world [8]. Expenditures associated with invasive alien species management also entail a high economic cost, mostly allocated to post-invasion management actions [9].

Carpobrotus edulis (L.) N.E. Br (Aizoaceae), commonly known as ice plant, is a wellknown invasive plant native to the Cape Region (South Africa). C. edulis invades coastal ecosystems with Mediterranean-type climates around the world, including mainly coastal sand dunes and cliffs, where they cause great negative impacts. In Europe, naturalized populations of Carpobrotus have been described since the beginning of the 20th century, and these species were originally introduced for soil stabilization and as an ornamental plant in gardens [10]. C. edulis is catalogued as an invasive species in several national legislations, 
and as a consequence many management actions have been conducted, mostly in southern Europe and California [10,11].

To date, most eradication programs for Carpobrotus are based on mechanical and chemical methods. Although mechanical methods appear to be suitable for small patches, management of dense mats by this method can be very costly and time-consuming. Moreover, invasive Carpobrotus species are capable of vigorous clonal growth, so management by mechanical methods does not necessarily prevent re-sprouts or the emergence of new ramets (asexual individuals) [10,12]. On the other hand, chemical methods, mostly based on application of glyphosate herbicide, have been successfully used to control Carpobrotus $[10,11,13,14]$. However, use of glyphosate to control Carpobrotus also entails negative effects to native vegetation, especially when applied directly in sandy soils $[10,14]$. Despite the effectiveness for native vegetation recovery [11], special caution has to be taken to adjust the dose of glyphosate to minimize its impacts on ecosystems [13].

C. edulis reproduces clonally with a radial structure of genetically identical ramets that form dense mats [15]. These ramets remain interconnected by creeping stems, produce roots after direct contact with soil and can survive even after they are disconnected from the rest of the clone. Clonal growth allows C. edulis to spread quickly horizontally to effectively colonize the surrounding area $[16,17]$. Physiological integration (i.e., the ability to share resources and other substances between connected modules) allows clonal plants to act as a cooperative system, buffering environmental stress [16,18-27]. Clonal traits, specifically physiological integration, are associated with plant invasiveness in different species [28-30], including Carpobrotus (for a review see [17]). Previous studies have tested the role of physiological integration in the expansion of Carpobrotus under different types of stress such as competition, nutrient deficiency, water shortage, shade and herbivory [16,31-36], but the effect of herbicide application on physiologically integrated clones of Carpobrotus has not been assessed yet.

Recently, Fos et al. (2021) have conducted a study to establish the minimum effective dose of glyphosate for Carpobrotus control, which was stated at $0.4 \mathrm{~g} / \mathrm{m}^{2}$ [13]. However, no previous study has been carried out to determine whether the effect of glyphosate differs according to the specific part of the clonal system where it is applied. Here, we studied the effects of glyphosate application on physiologically integrated clones of the invasive plant C. edulis. Specifically, we compared the effect of glyphosate application in basal and apical parts of connected (physiological integration allowed) and severed (physiological integration prevented) clonal fragments of C. edulis. Specifically, we asked the following questions: (1) Does physiological integration buffer the negative impact of glyphosate application on C. edulis? Because physiological integration allows clonal plants to act as a cooperative system, buffering stressful conditions, we predict that a reduction in growth and photochemical efficiency due to glyphosate application will be less accentuated in connected than in severed clonal fragments of $C$. edulis. (2) Do the effects of physiological integration differ when glyphosate is applied to the basal vs. the apical parts of the clonal system? Because resource transport between connected ramets of clonal plants usually occurs acropetally (from basal to apical ramets), we predict that the negative effect of glyphosate will be more pronounced when it is applied to the basal than to the apical parts. In other words, we predict that physiological integration will alleviate the negative effect of glyphosate application on apical parts, but not on basal parts.

\section{Materials and Methods}

\subsection{Plant Material and Experimental Design}

Thirty-six similar-sized un-rooted clonal fragments of $C$. edulis were collected in a coastal sand dune in Moledo, Caminha (Portugal) $\left(41^{\circ} 51^{\prime} 11^{\prime \prime} \mathrm{N}, 8^{\circ} 51^{\prime} 57^{\prime \prime} \mathrm{W}\right)$ in March 2021. Each fragment consisted of the youngest four ramets along a stem from the apex, and consequently all fragments were at a similar size and developmental stage. The two oldest ramets of the clonal fragment are hereinafter referred to as basal ramets, and the two youngest ramets are hereinafter referred to as apical ramets. The clonal fragments were 
collected from different clumps along the coastal sand dune in a relatively large area so that different clones were very likely to be included in the experiment. Each clonal fragment was planted in $22.5 \mathrm{~L}$ polystyrene tray ( 30 wide $\times 50$ long $\times 15 \mathrm{~cm}$ deep), filled with sand obtained from local coastal dunes inhabited by C. edulis.

The experimental design comprised two crossed factors: ramet connection (connected vs. severed) and glyphosate application (no glyphosate application, glyphosate applied on basal ramets, and glyphosate applied on apical ramets; Figure 1). In the connected treatment clonal fragments were left connected (physiological integration was allowed), and in the severed treatment they were disconnected by cutting the stem halfway between basal and apical ramets (physiological integration was prevented). Disconnection reflects the fact that disturbance frequently breaks clonal fragments into smaller groups under natural conditions $[37,38]$.

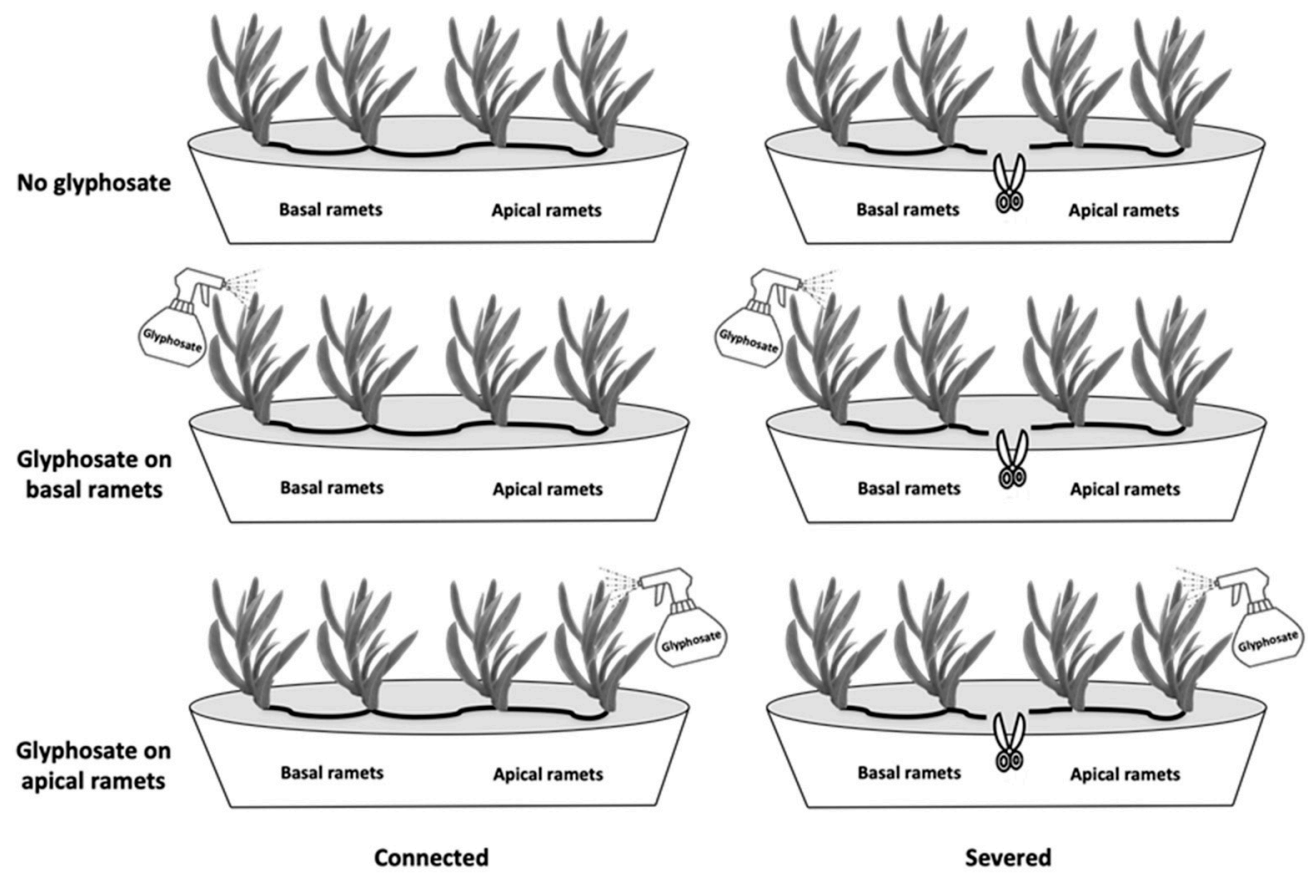

Figure 1. Schematic representation of experimental design. Basal and apical ramets under the different combinations of glyphosate application (no glyphosate, glyphosate application on basal ramets, and glyphosate application on apical ramets) and connection (connected, disconnected) are shown.

Glyphosate (360 g/L, ammonium salt; Touchdown Premium, Syngenta, Spain) was sprayed directly on leaves of apical ramets (in the treatment of glyphosate application on apical ramets) or basal ramets (in the treatment of glyphosate application on basal ramets) in a $2 \%$ solution, at doses of $0.06 \mathrm{~g} / \mathrm{m}^{2}$ (equivalent to about $8.3 \mathrm{~mL} / \mathrm{m}^{2}$ ). Glyphosate was applied using a hand-held bottle at a height of $20 \mathrm{~cm}$ above the ramets, ensuring a uniform wetting of the leaves. The glyphosate dose applied was around six times lower than the minimum effective dose to prevent Carpobrotus regrowth [13] and the recommended dose range of the European Food Safety Authority (EFSA 2017).

Clonal fragments were randomly assigned to each of the connection and glyphosate treatments, and each treatment was replicated six times. Before of the start of the experiment, the initial fresh mass of each clonal fragment was measured, showing no differences among treatments (ANOVA: $\mathrm{F}_{1,30}=0.012, p=0.915$, for connection; $\mathrm{F}_{1,30}=0.824, p=0.448$, for glyphosate; $\mathrm{F}_{1,30}=2.035, p=0.148$, for connection $\mathrm{x}$ glyphosate). The experiment was carried out in an experimental garden at the University of A Coruña (Spain). The experiment began on 12 April 2021 and continued for 105 days. The herbicide was added in a unique application on 26 April 2021, 35 days after the start of the experiment. By 
doing this we ensured that plants were healthy established before adding the herbicide, and therefore confounding effects were discarded.

\subsection{Measurements}

\subsubsection{Growth and Biomass Allocation}

At the end of the experiment, both basal and apical ramets were separated into roots and shoots (stems and leaves), dried at $60^{\circ} \mathrm{C}$ over $120 \mathrm{~h}$ and weighed to determine dry biomass. Then we calculated total biomass and root mass ratio (RMR, root mass/total mass) of the basal ramets, the apical ramets, and the whole clonal fragment (basal + apical ramets).

\subsubsection{Chlorophyll Fluorescence}

The maximum quantum yield of PSII (Fv/Fm) was determined using a hand held chlorophyll fluorometer (OS30p+, Opti-Sciences, Inc. Hudson, NH, USA). Fv/Fm was determined as the ratio $\left(\mathrm{Fm}-\mathrm{F}_{0}\right) / \mathrm{Fm}[39]$, where $\mathrm{F}_{0}$ and Fm are, respectively, the minimal and maximal fluorescence yield of a dark-adapted sample, with all PSII reaction centres fully open (i.e., all primary acceptors oxidized). This parameter was measured after a 30-min period of dark adaptation, to allow PSII reaction centres of the leaf to be fully open. The period of dark adaptation was achieved by the use of dark adaptation clips provided by the fluorometer manufacturer. $\mathrm{Fv} / \mathrm{Fm}$ is a measure of the photosynthetic process and estimates the efficiency of excitation energy capture by open PSII reaction centres during the light reaction of the photosynthesis [40], and is correlated with the amount of carbon gained per unit of light absorbed [41]. Chlorophyll fluorescence measurements were done on a fully formed leaf of the basal and apical ramets, and determined throughout the experiment at 0,35 and 70 days after glyphosate application.

\subsection{Statistical Analyses}

Differences in root, shoot, total biomass and RMR were analyzed using a two-way ANOVA, with connection (connected and disconnected) and glyphosate (no glyphosate application, glyphosate application on basal ramets and glyphosate application on apical ramets) as fixed effects. Analyses were performed separately for the basal ramets, the apical ramets and the whole clonal fragment. Differences between individual means were testing using a post hoc Tukey test. Differences in the maximum quantum yield of PSII (Fv/Fm) were determined by two-way repeated-measures ANOVA, with connection and glyphosate as between-subject effects and time as a within-subject effect, and were performed separately for basal and apical ramets. Significance levels were set at $p=0.05$. Analyses were conducted with IBM SPSS Statistics, version 27 (IBM Corp., Armonk, New York, NY, USA).

\section{Results}

\subsection{Growth and Biomass Allocation}

Connection significantly or tended to significantly $(p=0.055)$ affected root biomass and biomass allocation to roots (root mass ratio) of both basal and apical ramets (Table 1). Connection significantly increased root production (root mass and RMR) in basal ramets (Figure 2). On the contrary, apical ramets that remained connected reduced both their root mass and RMR (Figure 3). Interestingly, connection significantly interacted with glyphosate application to affect root production of basal ramets (Table 1): connection greatly increased root production of basal ramets under no glyphosate, had no significant effect when glyphosate was sprayed to basal ramets and decreased root production when glyphosate was applied to the apical ramets (Figure 2). Root biomass, shoot biomass, total biomass and RMR of basal ramets, apical ramets and whole clones were significantly affected by the glyphosate treatment (Table 1). In particular, biomass and RMR of both whole clones and basal ramets experienced a significant reduction when glyphosate was applied to the basal or apical ramets (Figures 2 and 4). Similarly, root mass and RMR of apical ramets also reduced when glyphosate was applied to either basal or apical parts of the clone (Figure 3). 
However, shoot mass and total mass of the apical ramets were not significantly reduced when glyphosate was sprayed over the basal ramets of the clone (Figure 3).

Table 1. Effects of connection, glyphosate and the interaction on the growth and biomass allocation of (A) basal ramets, (B) apical ramets and (C) whole clones. Degree of freedom, $\mathrm{F}$ and $p$ values of two-way ANOVA are given. Values of $p<0.05$ are shown in bold. See Figures $2-4$ for data.

\begin{tabular}{|c|c|c|c|c|c|c|}
\hline \multirow[b]{2}{*}{ Variable } & \multicolumn{2}{|c|}{ Connection (C) } & \multicolumn{2}{|c|}{ Glyphosate (G) } & \multicolumn{2}{|c|}{$\mathrm{C} \times \mathrm{G}$} \\
\hline & $F_{1,30}$ & $p$ & $F_{2,30}$ & $p$ & $F_{2,30}$ & $p$ \\
\hline \multicolumn{7}{|c|}{ (A) Basal ramets } \\
\hline Root biomass & 9.33 & 0.005 & 20.09 & $<0.001$ & 14.99 & $<0.001$ \\
\hline Shoot biomass & 1.86 & 0.182 & 6.39 & 0.005 & 0.93 & 0.407 \\
\hline Total biomass & 0.48 & 0.492 & 9.46 & $<0.001$ & 2.20 & 0.128 \\
\hline Root mass ratio & 15.40 & $<0.001$ & 26.24 & $<0.001$ & 18.89 & $<0.001$ \\
\hline \multicolumn{7}{|c|}{ (B) Apical ramets } \\
\hline Root biomass & 4.00 & 0.055 & 15.45 & $<0.001$ & 0.90 & 0.419 \\
\hline Shoot biomass & 2.00 & 0.167 & 7.90 & 0.002 & 0.23 & 0.796 \\
\hline Total biomass & 1.09 & 0.306 & 9.48 & $<0.001$ & 0.12 & 0.891 \\
\hline Root mass ratio & 13.30 & $<0.001$ & 19.58 & $<0.001$ & 2.68 & 0.085 \\
\hline \multicolumn{7}{|c|}{ (C) Whole clone } \\
\hline Root biomass & 0.83 & 0.369 & 27.17 & $<0.001$ & 5.54 & 0.009 \\
\hline Shoot biomass & 0.012 & 0.898 & 6.99 & 0.003 & 0.61 & 0.552 \\
\hline Total biomass & 0.07 & 0.800 & 10.19 & $<0.001$ & 0.85 & 0.436 \\
\hline Root mass ratio & 0.18 & 0.677 & 43.85 & $<0.001$ & 7.19 & 0.003 \\
\hline
\end{tabular}
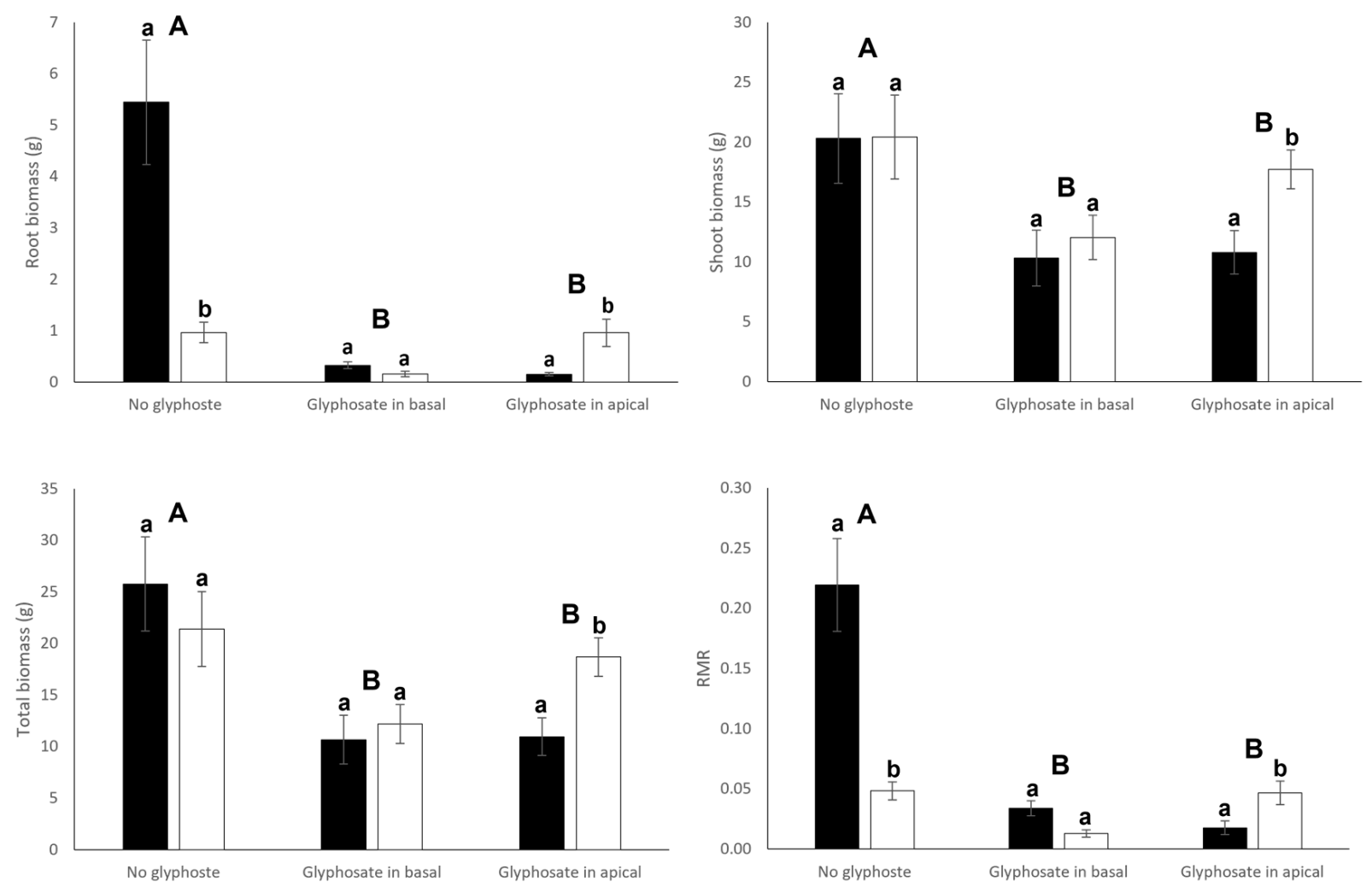

Figure 2. Root biomass, shoot biomass, total biomass and root mass ratio (RMR) of connected (filled bars) and severed (open bars) basal ramets. Mean \pm SE are shown. Uppercase letters indicate significant differences between glyphosate treatments and lowercase letters indicate significant differences between connection treatments (by Tukey test). See Table 1 for ANOVA results. 

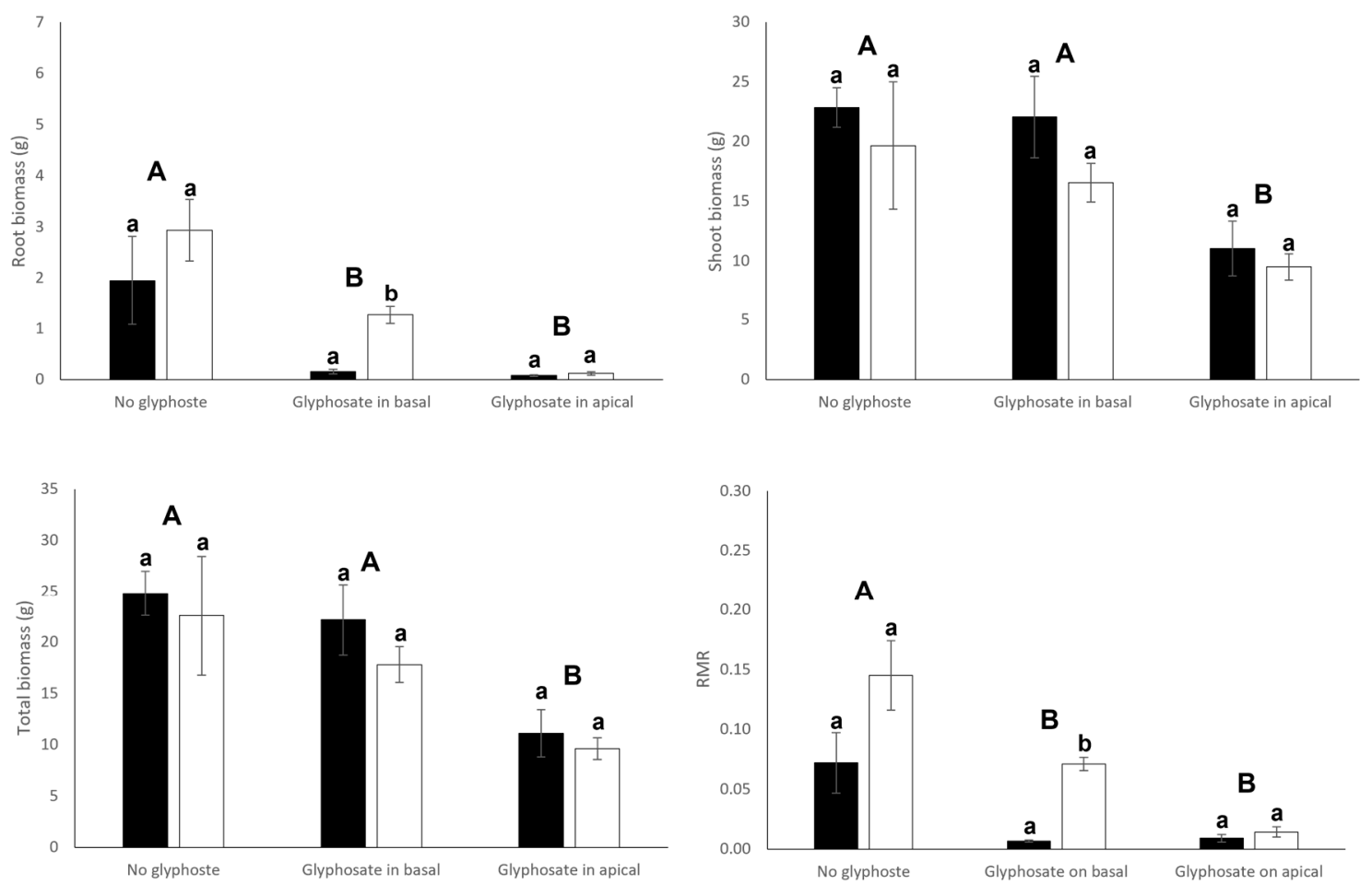

Figure 3. Root biomass, shoot biomass, total biomass, and root mass ratio (RMR) of connected (filled bars) and severed (open bars) apical ramets. Mean \pm SE are shown. Uppercase letters indicate significant differences between glyphosate treatments and lowercase letters indicate significant differences between connection treatments (by Tukey test). See Table 1 for ANOVA results.
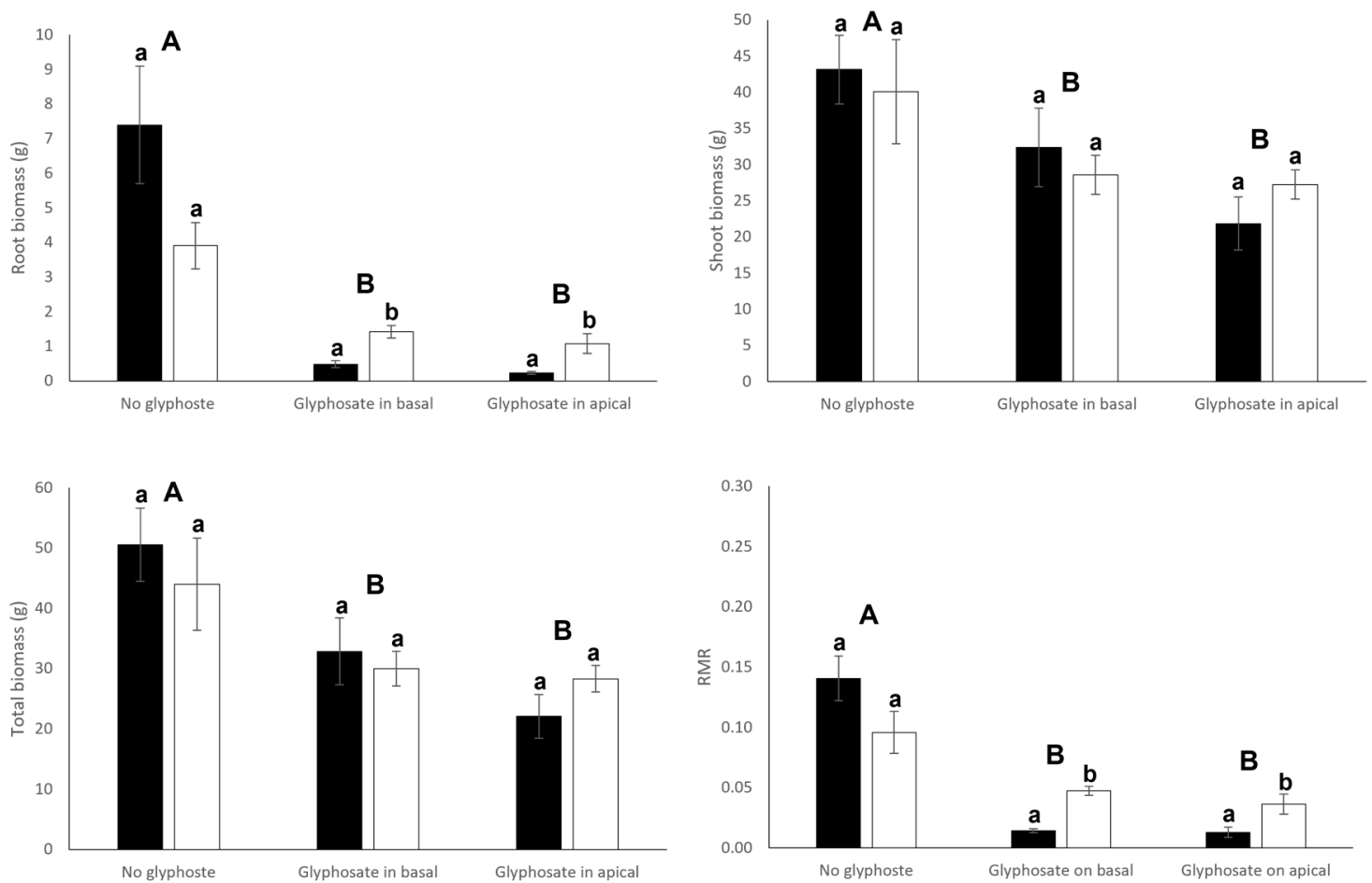

Figure 4. Root biomass, shoot biomass, total biomass and root mass ratio (RMR) of connected (filled bars) and severed (open bars) clonal fragments (i.e., basal plus apical ramets). Mean \pm SE are shown. Uppercase letters indicate significant differences between glyphosate treatments and lowercase letters indicate significant differences between connection treatments (by Tukey test). See Table 1 for ANOVA results. 


\subsection{Chlorophyll Fluorescence}

Glyphosate application significantly reduced Fv/Fm of both basal and apical ramets. Interestingly, this negative effect was significantly more evident in the disconnected than in the connected treatment (Connection x Glyphosate interaction in Table 2, Figure 5). The effect of glyphosate application on $\mathrm{Fv} / \mathrm{Fm}$ was only present in the ramets that directly received it, but was absent in the ramets that did not directly receive it. In other words, glyphosate application on basal ramets reduced $\mathrm{Fv} / \mathrm{Fm}$ of basal ramets, but had no effect on apical ramets even if they were connected to the basal ramets. Similarly, glyphosate application on apical ramets reduced $\mathrm{Fv} / \mathrm{Fm}$ of apical ramets, but had no effect on basal ramets even if they were interconnected. For both basal and apical ramets, the effect of glyphosate application on Fv/Fm changed significantly with time (Table 2): Fv/Fm reduced greatly from 0 days to 35 days after glyphosate application, but changed little from 35 days to 70 days (Figure 5). We also observed a significant three-way interaction of connection, glyphosate and time on Fv/Fm of apical ramets (Table 2): the negative effect at 35 days was similar between connected and severed treatment, but became smaller in connected than in severed treatment at 70 days (Figure 5B).

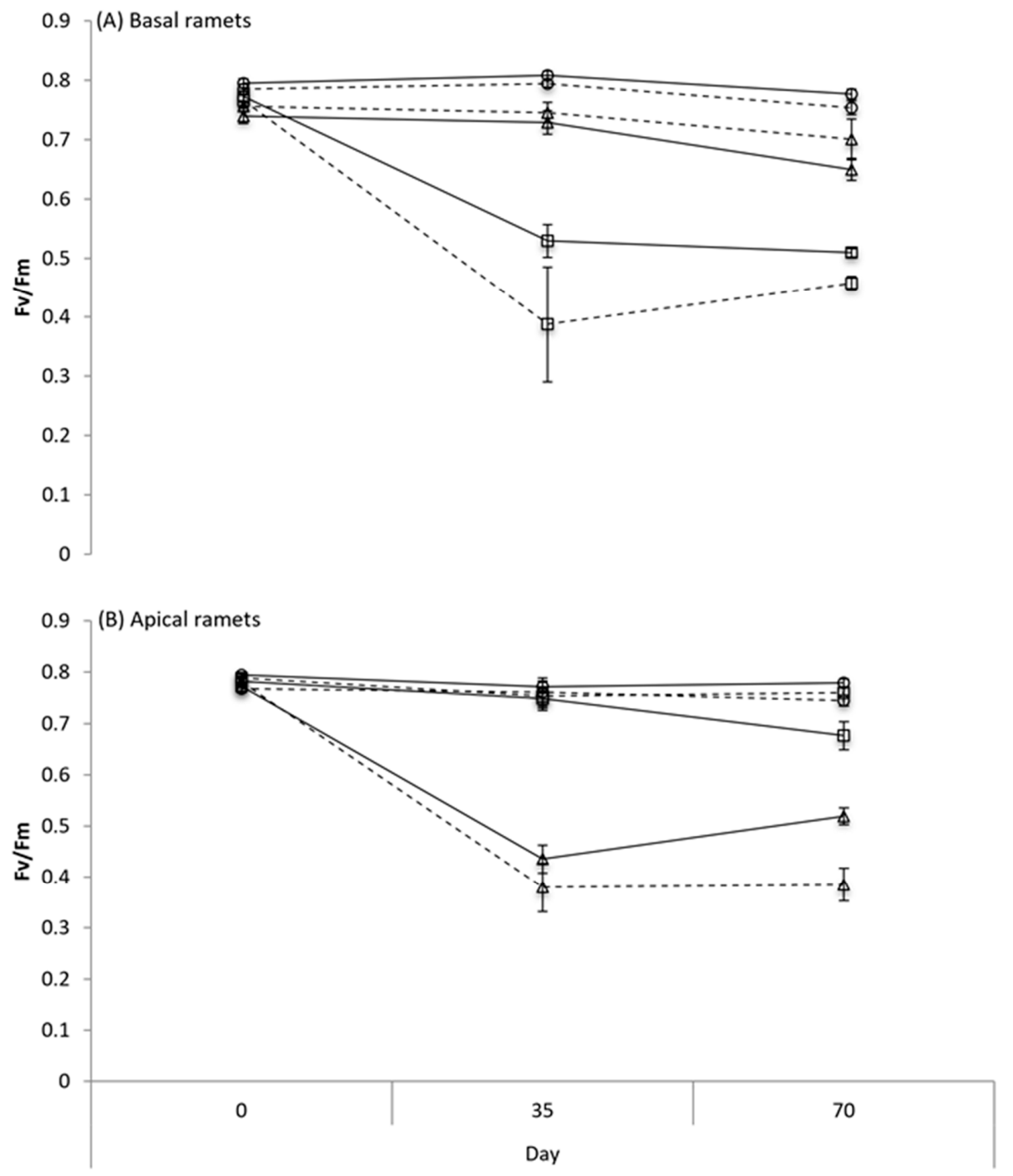

Figure 5. Changes of Fv/Fm (mean $\pm \mathrm{SE}$ ) over time in connected (solid lines) and severed (dashed lines) basal (A) and apical (B) ramets when glyphosate was applied to neither basal nor apical ramets (circles symbols), to basal ramets (square symbols) or to apical ramets (triangle symbols). See Table 2 for ANOVA results. 
Table 2. Effects of connection, glyphosate, time and their interactions on maximum quantum yield of photosystem PSII (Fv/Fm) of (A) basal ramets and (B) apical ramets. Degree of freedom, F and $p$ values of three-way ANOVA are given. Values of $p<0.05$ are shown in bold. See Figure 5 for data.

\begin{tabular}{|c|c|c|c|}
\hline Effect & df & $\mathbf{F}$ & $p$ \\
\hline \multicolumn{4}{|l|}{ (A) Basal ramets } \\
\hline \multicolumn{4}{|c|}{ Between-subject } \\
\hline Connection (C) & 1,30 & 1.73 & 0.198 \\
\hline Glyphosate (G) & 2,30 & 86.10 & $<0.001$ \\
\hline $\mathrm{C} \times \mathrm{G}$ & 2,30 & 3.99 & 0.029 \\
\hline \multicolumn{4}{|c|}{ Within-subject } \\
\hline Time $(\mathrm{T})$ & 2,60 & 39.85 & $<0.001$ \\
\hline $\mathrm{C} \times \mathrm{T}$ & 2,60 & 1.31 & 0.278 \\
\hline $\mathrm{G} \times \mathrm{T}$ & 4,60 & 25.73 & $<0.001$ \\
\hline$C \times G \times T$ & 4,60 & 1.19 & 0.323 \\
\hline \multicolumn{4}{|l|}{ (B) Apical ramets } \\
\hline \multicolumn{4}{|c|}{ Between-subject } \\
\hline Connection (C) & 1,30 & 5.00 & 0.033 \\
\hline Glyphosate (G) & 2,30 & 335.40 & $<0.001$ \\
\hline $\mathrm{C} \times \mathrm{G}$ & 2,30 & 11.50 & $<0.001$ \\
\hline \multicolumn{4}{|c|}{ Within-subject } \\
\hline Time $(\mathrm{T})$ & 2,60 & 85.66 & $<0.001$ \\
\hline $\mathrm{C} \times \mathrm{T}$ & 2,60 & 0.54 & 0.583 \\
\hline $\mathrm{G} \times \mathrm{T}$ & 4,60 & 50.95 & $<0.001$ \\
\hline$C \times G \times T$ & 4,60 & 3.88 & 0.008 \\
\hline
\end{tabular}

\section{Discussion}

In both the connected (physiological integration allowed) and severed (physiological integration prevented) treatment, we observed a significant reduction of biomass (root, shoot, and total biomass), and photochemical efficiency (estimated as the maximum quantum yield of PSII, Fv/Fm) in both basal and apical ramets after glyphosate application. These results confirm the damage caused by glyphosate, which in the appropriate dose is an efficient method for Carpobrotus control, as previously reported [11,13,14]. Visual effects of glyphosate at day 70 were similar to those reported by Fos et al. (2021) for a dose of $0.05 \mathrm{~g} / \mathrm{m}^{2}$ at day 84 , i.e., plants turned yellowish-brown but were still relatively succulent [13].

Contrary to our predictions, the negative impact of glyphosate application was not alleviated by physiological integration as glyphosate application reduced growth and photochemical efficiency similarly in the connected and severed treatments. Furthermore, this effect was independent of whether glyphosate was applied to the basal or the apical ramets. These results contrast with numerous previous findings showing a benefit of physiological integration, especially for apical developing ramets growing in stressful patches with, e.g., low nutrients [42], drought [34] and shade [24,26], salinity [43], pathogens [44], herbivores [45] and heavy metals [27,46].

Interestingly, our results showed a significant reduction in terms of total biomass in untreated basal ramets when they remained connected to apical ramets treated with glyphosate. This result was interpreted as a cost for basal fragments due to supporting severely stressed apical ramets. This penalization in growth for connected basal ramets was also extended to the whole clone, which also suffered a reduction in total biomass, especially when glyphosate was added to the apical ramets. Although physiological integration generally represents a benefit for the clone, it may also involve costs under some circumstances [22]. For instance, physiological integration may allow transport of pollutants or diseases negatively affecting other ramets despite being located in unstressed patches [18,47-49]. In fact, physiological integration may even cease when conditions suffered by dependent ramets are of severe stress [50,51]. Balance between costs and benefits of physiological integration can be dependent on the level of integration (i.e., capacity 
for sharing resources and other substances) and the environment (i.e., local conditions experienced by the ramets).

We propose two plausible explanations to justify the cost experienced by untreated basal ramets in our experiment. The first one is due to the excessive stress suffered by apical ramets under glyphosate-induced, excessive cost to basal ramets. Transport of resources to fully dependent apical ramets represents a cost for donor (basal) ramets. Similarly, Roiloa and Retuerto (2012) detected that basal ramets of the clonal herb F. vesca faced penalties for establishing their offspring in soils polluted by heavy metals [46]. Interestingly, these costs depended on the level of pollutions experienced by the offspring, with an increase in the growth reduction of the basal ramets in parallel with an increase in the degree of the metal pollution suffered by their supported apical ramets [46]. Cost reported by Roiloa and Retuerto (2012) was not due to basipetal transport of metals from contaminated apical ramets to un-contaminated basal ramets, but was probably caused by the supporting effort to severely stressed offspring [46].

The second explanation is that glyphosate was transported from treated apical ramets to untreated basal ramets, which reduced the growth of basal ramets. Glyphosate is a systemic herbicide, which may be translocated via the phloem of plants. A previous study has demonstrated the occurrence of a developmentally division of labour in C. edulis, characterized by task specialization implicit in the ontogeny of the modules [52]. Basal ramets specialize in acquisition of soil resources, which will be subsequently acropetally transported to apical ramets through xylem vessels. On the other hand, apical ramets specialize in the uptake of aboveground resources, and the obtained photo-assimilates can be basipetally transported to basal ramets through phloem vessels. Thus, glyphosate absorbed by leaves could also be transported via phloem from treated apical ramets to untreated basal ramets, but may not be transported acropetally. This could explain why basal ramets of $C$. edulis were negatively affected when glyphosate was applied to apical ramets, but apical ramets were not when glyphosate was applied to basal ramets. However, to confirm whether basipetal transport of glyphosate can occur but acropetal transport cannot, it would be necessary to use isotope labelling techniques to trace glyphosate movements within clones.

We should also note that the non-local effect of glyphosate detected in untreated basal ramets was only evident on biomass but not on photochemical efficiency. Similar results were found in connected ramets of strawberry, with a strong reduction in chlorophyll content in ramets sprayed with glyphosate but not in untreated connected siblings [53]. The absence of a non-local effect on basal ramets in terms of photochemical efficiency may indicate that basipetal transport of glyphosate did not occur so that the biomass cost observed in basal ramets was due to the huge resource demand made by the apical ramets growing under stressful conditions. Consequently, untreated basal ramets could maintain their photosynthetic activity, but the strong demand of resource from stressed apical ramets represented a constant sink that penalized the growth of the basal ramets.

Another interesting result is related to the effect of glyphosate on biomass partitioning pattern. Under control conditions (no glyphosate added) we observed a developmental division of labor triggered by integration, with an increase of the biomass allocated to roots in basal ramets (i.e., specialization to acquire soil resources) and a decrease of the biomass allocated to roots in the apical ramets (i.e., specialization to acquire aboveground resources). Similar results were described previously for $C$. edulis under homogeneous conditions [52]. However, our results showed that application of glyphosate to apical ramets inverted this response in basal ramets; thus, untreated basal ramets connected to apical ramets sprayed with glyphosate significantly reduced the proportional production of roots. A plausible explanation for this result is that the addition of glyphosate to the leaves of the apical ramets affected their photosynthetic capacity so that they could not maintain their function of division of labor (i.e., the acquisition of aboveground resources). To adapt to this new situation, basal ramets changed their pattern of biomass partitioning and allocated more biomass to capture aboveground resources in order to support their connected apical 
ramets that suffered from the negative effect of glyphosate. This explanation would also support our explanation that the negative effect observed in the basal ramets was due to the huge cost of maintaining the growth of their apical ramets highly stressed by glyphosate. While division of labor could occur even if glyphosate was applied on basal ramets, it cannot be maintained when glyphosate was applied on apical ramets, which consequently resulted in the growth reduction of the basal ramets.

\section{Conclusions}

With the objective of reducing as much as possible the negative impact of glyphosate addition applied in eradication programs, we should not only adjust the minimum effective dose [13] but also determine whether local application over specific parts of the C. edulis clump can maintain the effectiveness of glyphosate, as the latter can also reduce the use of the herbicide. Our results suggest that glyphosate application to only the apical parts can already efficiently restrict the growth of the whole clone of C. edulis. This application approach can greatly reduce the amount of glyphosate used and thus has both economical and ecological values. However, it should be taken into account that the application of glyphosate to the apical parts of the clonal system, presumably containing a lower density of ramets, could result in the herbicide reaching the soil more easily, with a consequent negative impact. To evaluate the robustness of this approach, field experiments should be conducted with $C$. edulis to test its effectiveness and application values. Although we conclude that glyphosate can be used for effective control of Carpobrotus, our results must not lead to complacency about use of herbicides, which can cause severe damage to habitats.

Author Contributions: S.R.R. conceived the study, ran the experiment and recorded the data. S.R.R., F.-H.Y. and R.B. wrote, reviewed and edited the manuscript. All authors have read and agreed to the published version of the manuscript.

Funding: This research received no external funding.

Institutional Review Board Statement: Not applicable.

Data Availability Statement: The data that support the findings of this study are available from the corresponding author, S.R.R, upon reasonable request.

Acknowledgments: We thank A.R. Blanco and G. Rodríguez for assistance with the harvest of the experiment.

Conflicts of Interest: The authors declare no conflict of interest.

\section{References}

1. Martínez, M.; Psuty, N. Coastal Dunes; Springer: Berlin/Heidelberg, Germany, 2008.

2. Mack, R.N.; Simberloff, D.; Lonsdale, W.M.; Evans, H.; Clout, M.; Bazzaz, F.A. Biotic invasions: Causes, epidemiology, global consequences, and control. Ecol. Appl. 2000, 10, 689-710. [CrossRef]

3. Richardson, D.M.; Pyšek, P. Fifty years of invasion ecology-The legacy of Charles Elton. Divers. Distrib. 2008, 14, 161-168. [CrossRef]

4. Hejda, M.; Pyšek, P.; Jarošík, V. Impact of invasive plants on the species richness, diversity and composition of invaded communities. J. Ecol. 2009, 97, 393-403. [CrossRef]

5. Strayer, D.L. Eight questions about invasions and ecosystem functioning. Ecol. Lett. 2012, 15, 1199-1210. [CrossRef]

6. Castro-Díez, P.; Pauchard, A.; Traveset, A.; Vilà, M. Linking the impacts of plant invasion on community functional structure and ecosystem properties. J. Veg. Sci. 2016, 27, 1233-1242. [CrossRef]

7. Bacher, S.; Blackburn, T.M.; Essl, F.; Genovesi, P.; Heikkilä, J.; Jeschke, J.M.; Jones, G.; Keller, R.; Kenis, M.; Kueffer, C.; et al. Socio-economic impact classification of alien taxa (SEICAT). Methods Ecol. Evol. 2018, 9, 159-168. [CrossRef]

8. Robertson, P.A.; Mill, A.; Novoa, A.; Jeschke, J.M.; Essl, F.; Gallardo, B.; Geist, J.; Jarić, I.; Lambin, X.; Musseau, C.; et al. A proposed unified framework to describe the management of biological invasions. Biol. Invas. 2020, 22, 2633-2645. [CrossRef]

9. Diagne, C.; Leroy, B.; Vaissière, A.C.; Gozlan, R.E.; Roiz, D.; Jarić, I.; Salles, J.M.; Bradshaw, C.J.A.; Courchamp, F. High and rising economic costs of biological invasions worldwide. Nature 2021, 592, 571-576. [CrossRef]

10. Campoy, J.G.; Acosta, A.T.R.; Affre, L.; Barreiro, R.; Brundu, G.; Buisson, E.; González, L.; Lema, M.; Novoa, A.; Retuerto, R.; et al. Monographs of invasive plants in Europe: Carpobrotus. Bot. Lett. 2018, 165, 440-475. [CrossRef] 
11. Lazzaro, L.; Tondini, E.; Lombardi, L.; Giunti, M. The eradication of Carpobrotus spp. in the sand dune ecosystem at Sterpaia (Italy, Tuscany): Indications from a successful experience. Biologia 2020, 75, 199208. [CrossRef]

12. Chenot, J.; Affre, L.; Gros, R.; Dubois, L.; Malecki, S.; Passetti, A.; Aboucaya, A.; Buisson, E. Eradication of invasive Carpobrotus sp.: Effects on soil and vegetation. Restor. Ecol. 2018, 26, 106-113. [CrossRef]

13. Fos, M.; Sanz, B.; Sanchis, E. Carpobrotus management in a Mediterranean sand dune ecosystem: Minimum effective glyphosate dose and an evaluation of tarping. J. Ecol. Eng. 2021, 22, 57-66. [CrossRef]

14. Fos, M.; Sanz, B.; Sanchis, E. The use of glyphosate for Carpobrotus eradication in sand dune ecosystems: Evaluation of the potential effects on the reintroduction of native plants. Plant Biosyst. 2021. [CrossRef]

15. Wisura, W.; Glen, H.F. The South African species of Carpobrotus (Mesembryanthema-Aizoaceae). Contrib. Bolus Herb. 1993, 15, 76-107.

16. Roiloa, S.R.; Rodríguez-Echeverría, S.; de la Peña, E.; Freitas, H. Physiological integration increases the survival and growth of the clonal invader Carpobrotus edulis. Biol. Invas. 2010, 12, 1815-1823. [CrossRef]

17. Roiloa, S.R. Clonal traits and plant invasiveness: The case of Carpobrotus N.E.Br. (Aizoaceae). Perspect. Plant Ecol. Evol. Syst. 2019, 40, 125479. [CrossRef]

18. Van Groenendael, J.M.; de Kroon, H. Clonal Growth in Plants: Regulation and Function; SPB Academic Publishing: Hague, The Netherlands, 1990.

19. Si, C.; Alpert, P.; Zhang, J.F.; Lin, J.; Wang, Y.Y.; Hong, M.M.; Roiloa, S.R.; Yu, F.H. Capacity for clonal integration in introduced versus native clones of the invasive plant Hydrocotyle vulgaris. Sci. Total Environ. 2020, 745, 141056. [CrossRef]

20. Wang, J.; Xu, T.; Wang, Y.; Li, G.; Abdullah, I.; Zhong, Z.; Liu, J.; Zhu, W.; Wang, L.; Wang, D.; et al. A meta-analysis of effects of physiological integration in clonal plants under homogeneous vs. heterogeneous environments. Funct. Ecol. 2021, 35, 578-589. [CrossRef]

21. Lu, H.Z.; Brooker, R.; Song, L.; Liu, W.-Y.; Sack, L.; Zhang, J.-L.; Yu, F.-H. When facilitation meets clonal integration in forest canopies. New Phytol. 2020, 225, 135-142. [CrossRef]

22. Gao, F.-L.; Alpert, P.; Yu, F.H. Parasitism induces negative effects of physiological integration in a clonal plant. New Phytol. 2021, 229, 585-592. [CrossRef] [PubMed]

23. Hartnett, D.C.; Bazzaz, F.A. Physiological integration among intraclonal ramets in Solidago canadensis. Ecology 1983, 64, 779-788. [CrossRef]

24. Slade, A.J.; Hutchings, M.J. An analysis of the costs and benefits of physiological integration between ramets in the clonal perennial herb Glechoma hederacea. Oecologia 1987, 73, 425-431. [CrossRef] [PubMed]

25. Alpert, P. Clonal integration in Fragaria chiloensis differs between populations: Ramets from grassland are selfish. Oecologia 1999, 120, 69-76. [CrossRef] [PubMed]

26. Saitoh, T.; Seiwa, K.; Nishiwaki, A. Importance of physiological integration of dwarf bamboo to persistence in forest understorey: A field experiment. J. Ecol. 2002, 90, 78-85. [CrossRef]

27. Roiloa, S.R.; Retuerto, R. Physiological integration ameliorates effects of serpentine soils in the clonal herb Fragaria vesca. Physiol. Plantarum 2006, 128, 662-676. [CrossRef]

28. Song, Y.B.; Yu, F.H.; Keser, L.H.; Dawson, W.; Fischer, M.; Dong, M.; van Kleunen, M. United we stand, divided we fall: A meta-analysis of experiments on clonal integration and its relationship to invasiveness. Oecologia 2013, 171, 317-327. [CrossRef]

29. Wang, Y.J.; Müller-Schärer, H.; van Kleunen, M.; Cai, A.M.; Zhang, P.; Yan, R.; Dong, B.C.; Yu, F.H. Invasive alien plants benefit more from clonal integration in heterogeneous environments than natives. New Phytol. 2017, 216, 1072-1078. [CrossRef]

30. Roiloa, S.R.; Yu, F.-H.; Barreiro, R. Plant invasions: Mechanisms, impacts and management. Flora 2020, 267, 151603. [CrossRef]

31. Roiloa, S.R.; Rodríguez-Echeverría, S.; López-Otero, A.; Retuerto, R.; Freitas, H. Adaptive plasticity to heterogeneous environments increases capacity for division of labor in the clonal invader Carpobrotus edulis (Aizoaceae). Am. J. Bot. 2014, 101, 1301-1308. [CrossRef] [PubMed]

32. Roiloa, S.R.; Retuerto, R.; Campoy, J.G.; Novoa, A.; Barreiro, R. Division of labour brings greater benefits to clones of Carpobrotus edulis in the non-native range: Evidence for rapid adaptive evolution. Front. Plant Sci. 2016, 7, 349. [CrossRef]

33. Roiloa, S.R.; Alpert, P.; Barreiro, L. Differences in physiological integration between invasive and noninvasive introduced clonal species of Carpobrotus. J. Plant Ecol. 2019, 12, 972-981. [CrossRef]

34. Lechuga-Lago, Y.; Sixto-Ruiz, M.; Roiloa, S.R.; González, L. Clonal integration facilitates the colonization of drought environments by plant invaders. AoB Plants 2016, 8, plw023. [CrossRef]

35. Campoy, J.G.; Retuerto, R.; Roiloa, S.R. Resource sharing strategies in ecotypes of the invasive clonal plant Carpobrotus edulis: Specialization for abundance or scarcity of resources. J. Plant Ecol. 2017, 10, 681-691.

36. Rodríguez, J.; Calbi, M.; Roiloa, S.R.; González, L. Herbivory induced non-local responses of the clonal invader Carpobrotus edulis are not mediated by clonal integration. Sci. Total Environ. 2018, 633, 1041-1050. [CrossRef]

37. Stuefer, J.F.; Huber, H. The role of stolon internodes for ramet survival after clone fragmentation in Potentilla anserina. Ecol. Lett. 1999, 2, 135-139. [CrossRef]

38. Latzel, V.; Klimešová, J. Fitness of resprouters versus seeders in relation to nutrient availability in two Plantago species. Acta Oecol. 2009, 35, 541-547. [CrossRef] 
39. Bolhàr-Nordenkampf, H.R.; Long, S.P.; Baker, N.R.; Öquist, G.; Scheiber, U.; Lechner, E.G. Chlorophyll fluorescence as a probe of the photosynthetic competence of leaves in the field: A review of current instrumentation. Funct. Ecol. 1989, 3, 497-514. [CrossRef]

40. Bolhàr-Nordenkampf, H.R.; Öquist, G. Chlorophyll fluorescence-A tool in photosynthesis research. In Photosynthesis and Production in a Changing Environment; Hall, D.O., Scurlock, J.M.O., Bolhàr-Nordenkampf, H.R., Leegood, R.C., Long, S.P., Eds.; Chapman and Hall: London, UK, 1993; pp. 193-206.

41. Butler, W.; Kitajima, M. Fluorescence quenching in photosystem II of chloroplasts. Biochim. Biophys. Acta 1975, 376, 116-125. [CrossRef]

42. Evans, J.P. Nitrogen translocation in a clonal dune perennial Hydrocotyle bonariensis. Oecologia 1988, 77, 64-68. [CrossRef]

43. Salzman, A.G.; Parker, M.A. Neighbors ameliorate local salinity stress for a rhizomatous plant in a heterogeneous environment. Oecologia 1985, 65, 273-277. [CrossRef]

44. D'Hertefeldt, T.; van der Putten, W.H. Physiological integration of the clonal plant Carex arenaria and its response to soil-borne pathogens. Oikos 1998, 81, 229-237. [CrossRef]

45. Portela, R.; Dong, B.C.; Yu, F.H.; Barreiro, R.; Roiloa, S.R. Effects of physiological integration on defense strategies against herbivory by the clonal plant Alternanthera philoxeroides. J. Plant Ecol. 2019, 12, 662-672. [CrossRef]

46. Roiloa, S.R.; Retuerto, R. Clonal integration in Fragaria vesca growing in metal-polluted soils: Parents face penalties for establishing their offspring in unsuitable environments. Ecol. Res. 2012, 27, 95-106. [CrossRef]

47. Pitelka, L.F.; Ashmun, J.W. Population Biology and Evolution of Clonal Organisms; Jackson, J.B.C., Buss, L.W., Cook, R.E., Eds.; Yale University Press: New Haven, CT, USA, 1985; pp. 339-435.

48. Jónsdóttir, I.S.; Watson, M.A. Extensive physiological integration: An adaptive trait in resource-poor environments? In The Ecology and Evolution of Clonal Plants; de Kroon, H., van Groenendael, J., Eds.; Backhuys Publishers: Leiden, The Netherlands, 1997; pp. 109-136.

49. Outridge, P.M.; Hutchinson, T.C. Effects of cadmium on ramet integration and resource allocation in the clonal fern Salvinia molesta. Oecologia 1990, 84, 215-223. [CrossRef] [PubMed]

50. Ong, C.K.; Marshall, C. The growth and survival of severely-shaded tillers in Lolium perenne L. Ann. Bot. 1979, 43, 147-155. [CrossRef]

51. Jónsdóttir, I.S.; Callaghan, T.V. Localized defoliation stress and the movement of 14C-photoassimilates between tillers of Carex bigelowii. Oikos 1989, 54, 211-219. [CrossRef]

52. Roiloa, S.R.; Rodríguez-Echeverría, S.; Freitas, H.; Retuerto, R. Developmentally-programmed division of labour in the clonal invader Carpobrotus edulis. Biol. Invasions 2013, 15, 1895-1905. [CrossRef]

53. Savini, G.; Giorgi, V.; Scarano, E.; Neri, D. Strawberry plant relationship through the stolon. Physiol. Plantarum 2008, 134, 421-429. [CrossRef] 